\title{
Dynamic left ventricular outflow tract obstruction in living donor liver transplantation recipients -A report of two cases-
}

\author{
Ae Ryoung Lee, Young-Ri Kim, Ji-Sun Ham, Sangmin Maria Lee, and Gaab-Soo Kim \\ Department of Anesthesiology and Pain Medicine, Samsung Medical Center, Seoul, Korea
}

We present two cases of dynamic left ventricular outflow tract obstruction in 2 patients who were undergoing living donor liver transplantation. On the preoperative transthoracic echocardiography, the first patient showed normal ventricular function and a normal wall thickness, but severe hemodynamic deterioration developed during the anhepatic period and this was further aggravated after reperfusion in spite of volume resuscitation and catecholamine therapy. Intraoperative transesophageal echocardiography revealed the systolic anterior motion of the mitral valve leaflet together with left ventricular outflow tract obstruction. The second patient showed left ventricular hypertrophy with left ventricular outflow tract obstruction on the preoperative echocardiography. Intraoperative transesophageal echocardiography was used to guide fluid administration and the hemodynamic management throughout the procedure and a temporary portocaval shunt was established to mitigate the venous pooling during the anhepatic period. The purpose of this report is to emphasize the clinical significance of dynamic left ventricular outflow tract obstruction in patients who are undergoing living donor liver transplantation and the role of intraoperative echocardiography to detect and manage it. (Korean J Anesthesiol 2010; 59: S128-S132)

Key Words: Dynamic left ventricular outflow tract obstruction, Intraoperative transesophageal echocardiography, Living donor liver transplantation.

Dynamic left ventricular outflow tract obstruction (LVOTO) occurs in patients with [1] or without hypertrophic cardiomyopathy [2-5]. We present here two cases of dynamic LVOTO in patients who were undergoing living donor liver transplantation (LDLT). Anesthesiologists are frequently challenged during liver transplantation (LT) due to a large volume shift secondary to the surgical and medical bleeding and caval clamping, the low systemic vascular resistance and postreperfusion syndrome [6]. Additionally, the coexisting cardiac dysfunction and a small graft volume-to size due to LDLT required more delicate fluid management in our cases. Intraoperative transesophageal echocardiography (TEE) may be highly useful tool to monitor the intracavitary volume status and contractility for patients with dynamic LVOTO during a LDLT procedure.

Received: April 14, 2010. Revised: 1st, May 11, 2010; 2nd, June 21, 2010. Accepted: July 9, 2010.

Corresponding author: Gaab-Soo Kim, M.D., Department of Anesthesiology and Pain Medicine, Samsung Medical Center, 50, Ilwon-dong, Gangnam-gu, Seoul 135-710, Korea. Tel: 82-2-3410-0360, Fax: 82-2-3410-0361, E-mail: gskim@skku.edu

(c) This is an open-access article distributed under the terms of the Creative Commons Attribution Non-Commercial License (http:// creativecommons.org/licenses/by-nc/3.0/), which permits unrestricted non-commercial use, distribution, and reproduction in any medium, provided the original work is properly cited. 


\section{Case Reports}

\section{Case 1}

A 49-year-old man (body weight: $86 \mathrm{~kg}$, height: $169 \mathrm{~cm}$ ) who was diagnosed as having hepatocellular carcinoma with liver cirrhosis due to hepatitis B virus (Child-Pugh grade C, MELD score 14) presented for LDLT. His past medical history revealed diabetes mellitus that was well controlled with an oral hypoglycemic agent. The abnormal results of preoperative laboratory testing were as follows: aspartate transminase (AST): $59 \mathrm{U} / \mathrm{L}$, total bilirubin: $3.1 \mathrm{mg} / \mathrm{dl}$, albumin: $2.4 \mathrm{~g} / \mathrm{dl}$, platelets: 91,000/ml. The ECG and chest X-ray were within normal limits. Preoperative transthoracic echocardiography (TTE) showed diastolic dysfunction grade 2 with left atrial enlargement. No left ventricular hypertrophy and LVOTO were identified (Fig. 1).

Anesthesia was induced with thiopental sodium $5 \mathrm{mg} / \mathrm{kg}$ and vecuronium $0.1 \mathrm{mg} / \mathrm{kg}$ and it was maintained with desflurane

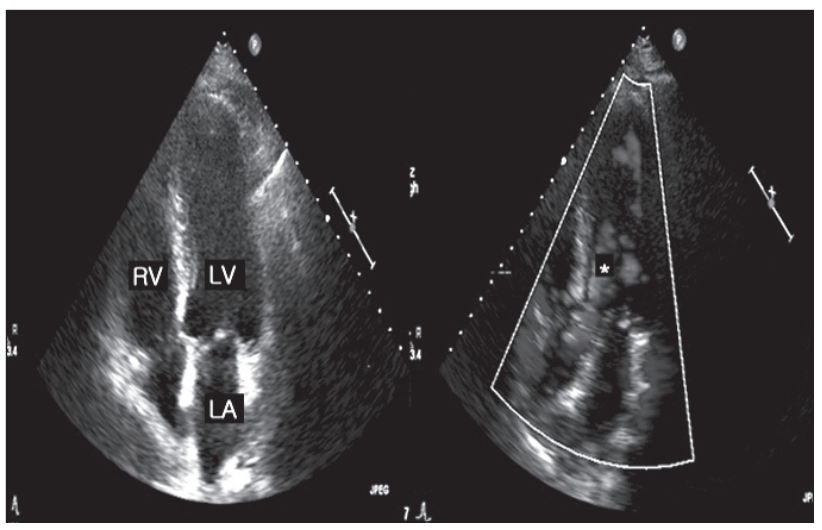

Fig. 1. The preoperative transthoracic echocardiography showed no left ventricular hypertrophy, a normal flow pattern in the left ventricular outflow tract $\left(^{*}\right)$ and no systolic anterior motion of the mitral leaflet in case 1 . The heart rate was $75-80$ beats $/ \mathrm{min}$. in air and oxygen. The routine vascular access consisted of a 9 Fr introducer (Advanced Venous Access ${ }^{\circledR}$ ) on the right internal jugular vein, a pulmonary artery catheter and two arterial catheters on the radial artery and femoral artery respectively, and a femoral venous catheter. After anesthetic induction, the vital signs were stable and the intraoperative course was unremarkable during the preanhepatic phase (Table 1).

The anhepatic phase began 3 hours 30 minutes after anesthetic induction, and hemodynamic instability abruptly developed. The hemodynamic instability improved with a large volume of fluids and blood products (crystalloid solution 10,500 $\mathrm{ml}$, colloid solution 1,200 ml, Cell Saver autotransfusion $978 \mathrm{ml}$ and leukocyte-depleted red blood cells (LDRBCs) 2 units for 2 hours) and catecholamine infusion (dopamine $5 \mu \mathrm{g} / \mathrm{kg} / \mathrm{min}$ and norepinephrine $0.1 \mu \mathrm{g} / \mathrm{kg} / \mathrm{min}$ ) (Table 1 ).

Reperfusion began 2 hours 20 minutes after portal vein clamping, and the hemodynamic instability further deteriorated. We administered a large volume of fluids and blood products (crystalloid solution 3,400 ml, Cell Saver autotransfusion $500 \mathrm{ml}$ and fresh frozen plasma (FFP) 2 units in 1 hour) and increased the doses of catecholamines (norepinephrine $0.3 \mu \mathrm{g} / \mathrm{kg} / \mathrm{min}$ ) (Table 1). Two hours and 30 minutes after reperfusion, the endtidal $\mathrm{CO}_{2}$ was suddenly decreased and the ST segment of the ECG was elevated; the hemodynamic instability did not improve despite intravascular volume replacement and increased doses of catecholamines (dopamine $10 \mu \mathrm{g} / \mathrm{kg} / \mathrm{min}$, norepinephrine $0.1 \mu \mathrm{g} / \mathrm{kg} / \mathrm{min}$ and epinephrine $0.1 \mu \mathrm{g} / \mathrm{kg} / \mathrm{min}$ ) (Table 1). As there was preoperative diastolic dysfunction, we inserted a TEE to accurately evaluate the cardiac function at 3 hours and 30 minutes after reperfusion. The TEE evaluation revealed signs of dynamic LVOTO, including systolic anterior motion (SAM) and eccentric mildto-moderate mitral regurgitation. Based on the TEE findings, the epinephrine infusion $(0.1 \mu \mathrm{g} / \mathrm{kg} / \mathrm{min})$ was immediately discontinued, esmolol infusion $(30 \mu \mathrm{g} / \mathrm{kg} / \mathrm{min})$ was initiated

Table 1. The Hemodynamic Data and Administered Catecholamines in Case 1

\begin{tabular}{|c|c|c|c|c|c|c|c|}
\hline & $\mathrm{I}+1 \mathrm{hr}$ & $\mathrm{I}+2 \mathrm{hr}$ & $\mathrm{II}+1 \mathrm{hr}$ & $\mathrm{II}+2 \mathrm{hr}$ & $\mathrm{III}+1 \mathrm{hr}$ & $\mathrm{III}+3 \mathrm{hr}$ & $\mathrm{III}+7 \mathrm{hr}$ \\
\hline \multicolumn{8}{|c|}{ Hemodynamic data } \\
\hline HR & 63 & 85 & 114 & 118 & 120 & 128 & 87 \\
\hline $\mathrm{BP}$ & $100 / 55(68)$ & $108 / 57(73)$ & $101 / 56(77)$ & $87 / 49(61)$ & $94 / 54(67)$ & $80 / 48(59)$ & $101 / 50(66)$ \\
\hline CVP & 8 & 8 & 4 & 3 & 10 & 7 & 12 \\
\hline $\mathrm{CO}$ & 7.7 & 7.2 & 7 & 6.3 & 9.4 & 4.3 & 6.4 \\
\hline SVR & 623 & 722 & 834 & 737 & 485 & 967 & 675 \\
\hline RVEDV & 272 & 265 & 165 & 157 & 195 & 134 & 209 \\
\hline \multicolumn{8}{|c|}{ Infused catecholamines } \\
\hline DA & 3 & 5 & 5 & 5 & 5 & 10 & 5 \\
\hline $\mathrm{NE}$ & & & 0.05 & 0.1 & 0.3 & 0.1 & 0.5 \\
\hline $\mathrm{EP}$ & & & & & & 0.1 & \\
\hline
\end{tabular}

I: preanhepatic period, II: anhepatic period, III: postreperfusion period, HR (beats/min): heat rate, BP (mmHg): blood pressure, CVP (mmHg): central venous pressure, CO (L/min): cardiac output, SVR (dyn.s. $\left.\mathrm{cm}^{-5}\right)$ : systemic vascular resistance, RVEDV (ml): right ventricular enddiastolic volume, DA $(\mu \mathrm{g} / \mathrm{kg} / \mathrm{min})$ : dopamine, $\mathrm{NE}(\mu \mathrm{g} / \mathrm{kg} / \mathrm{min})$ : norepinephrine, $\mathrm{EP}(\mu \mathrm{g} / \mathrm{kg} / \mathrm{min})$ : epinephrine. 

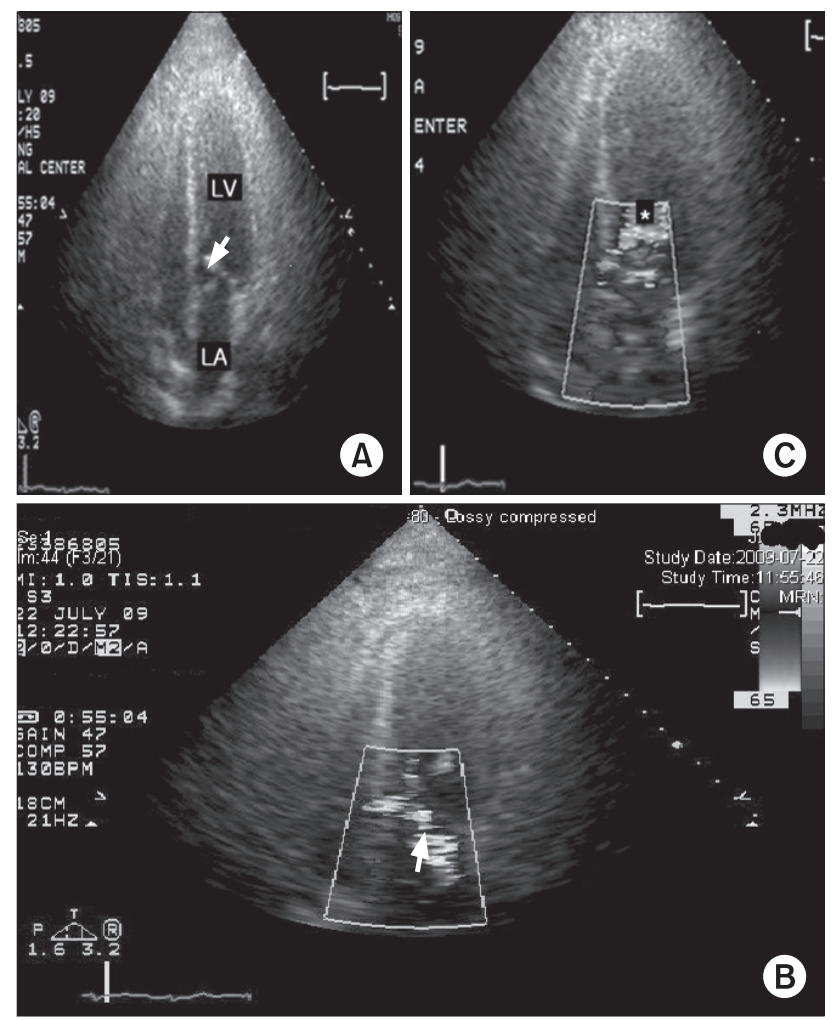

Fig. 2. The postoperative transthoracic echocardiography with color Doppler in case 1. (A) Systolic anterior motion of the anterior mitral valve leaflet (white arrow). (B) Color Doppler shows mild MR (white arrow) and (C) flow acceleration in the left ventricular outflow tract $\left(^{*}\right)$.

and several $100 \mu \mathrm{g}$ boluses of phenyleprine and aggressive volume resuscitation were performed (crystalloid solution 1,400 $\mathrm{ml}$, colloid solution $500 \mathrm{ml}$, Cell Saver autotransfusion 1,071 $\mathrm{ml}$, FFP 2 units for 1 hour). Afterward, the vital signs gradually became stable and the operation ended uneventfully (Table 1). The total infused volume included crystalloid solution: 26,400 ml, colloid solution: 2,650 ml, Cell Saver autotransfusion: 4,071 ml, LDRBCs: 5 units, FFP: 8 units and cryoprecipitate: 9 units. Postoperatively, large volumes of fluids and blood products were necessary to stably maintain the hemodynamics and the decreasing the dose of vasopressors was not possible. On second postoperative day, the TTE revealed the SAM with dynamic LVOTO (Fig. 2A). The color doppler showed mild mitral regurgitation (Fig. 2B) and flow acceleration in the LVOT (Fig. 2C). The patient underwent reoperation for control of the surgical bleeding on postoperative day 3 . He was discharged on postoperative day 42 .

\section{Case 2}

A 45-year-old man (body weight: $84 \mathrm{~kg}$, height: $180 \mathrm{~cm}$ ) was diagnosed with liver cirrhosis due to hepatitis $\mathrm{C}$ virus (Child-
Pugh grade C, MELD score 40) and he presented for LDLT. He had oliguric acute renal failure caused by hepatorenal syndrome, and this required continuous renal replacement therapy. The abnormal results of the preoperative laboratory testing were as follows: AST: $56 \mathrm{U} / \mathrm{L}$, alkaline phosphatase $35 \mathrm{U} / \mathrm{L}$, GGT (Gamma( $\gamma$ )-Glutamyl Transferase): $20 \mathrm{U} / \mathrm{L}$, total bilirubin: $12.5 \mathrm{mg} / \mathrm{dl}$, albumin: $2.6 \mathrm{~g} / \mathrm{dl}$, BUN (blood urea nitrogen): 31.7 $\mathrm{mg} / \mathrm{dl}$, creatinine: $3.75 \mathrm{mg} / \mathrm{dl}$, platelets: $35,000 / \mathrm{ml}$ and the prothrombin time (INR): 2.71 sodium $129 \mathrm{mEq} / \mathrm{L}$. The other laboratory testing and ECG were within the normal limits. However, the chest X-ray showed pulmonary edema on the bilateral lung fields. The preoperative TTE revealed asymmetric septal hypertrophy (the thickness of the interventricular septum and left ventricular posterior wall was $29 \mathrm{~mm}$ and 9 mm, respectively) with LVOTO. The mean pressure gradient of the LVOT was $80 \mathrm{mmHg}$. The color doppler showed eccentric moderate mitral regurgitation due to SAM. There was also grade 2 diastolic dysfunction. He experienced occasional hypotension (mean arterial pressure: $40 \mathrm{mmHg}$ ) accompanied by drowsy mentality, dizziness, blurred vision and chest discomfort caused by aggravation of the LVOTO due to volume depletion.

Anesthesia was induced with etomidate $0.2 \mathrm{mg} / \mathrm{kg}$ and atracurium $0.5 \mathrm{mg} / \mathrm{kg}$ and it was maintained with desflurane in air and oxygen. A 9 Fr introducer (Advanced Venous Access ${ }^{\circledR}$ ) was placed on the right internal jugular vein, and a pulmonary artery catheter and two arterial catheters were placed on the radial artery and femoral artery, respectively, and a femoral venous catheter were placed for routine vascular access. The TEE probe was gently inserted and there was no variceal bleeding. There were no noticeable changes of the LVOTO and SAM compared to the preoperative findings. The vital signs were stable during induction, but the blood pressure began to decrease 20 minutes later. The favorable response to phenylephrine $100 \mu \mathrm{g}$ bolus was confirmed, and then continuous infusion of norephinephrine was started at $0.05 \mu \mathrm{g} /$ $\mathrm{kg} / \mathrm{min}$ and this was adjusted in the range of $0.05-0.2 \mu \mathrm{g} / \mathrm{kg} /$ min along with maintaining the intravascular volume.

After bolus phenylephrine $100 \mu \mathrm{g}$ and increasing the norephnephrine dose to $0.25 \mu \mathrm{g} / \mathrm{kg} / \mathrm{min}$, the anhepatic phase began and a portocaval shunt was created to mitigate the venous pooling. The patient's intermittent hypotension was treated with intravascular volume expansion and bolus phenylephrine, and the norephinephrine dose was increased to $0.3 \mu \mathrm{g} / \mathrm{kg} / \mathrm{min}$. The infused fluid and blood products were crystalloid solution 1,900 $\mathrm{ml}$, half saline 5,600 ml, colloid solution 2,450 ml, Cell Saver autotransfusion 1,355 ml, LDRBCs 2 units, FFP 2 units and cryoprecipitate 6 units until 1 hour after the anhepatic phase.

Reperfusion began after a $100 \mu \mathrm{g}$ bolus of phenylephrine. Milder reperfusion syndrome occurred and the patient 
spontaneously recovered. There were no noticeable changes of the LVOTO and SAM compared to the initial findings after induction. The rest of the operation was relatively uneventful with maintaining the intravascular volumeand continuous infusion of norepinephrine at $0.4-0.6 \mu \mathrm{g} / \mathrm{kg} / \mathrm{min}$. The total administered volume included crystalloid solution 7,700 ml, half saline 7,300 ml, colloid solution 2,970 ml, $5 \%$ dextrose water $200 \mathrm{ml}$, Cell Saver autotransfusion 3,701 ml, LDRBCs 5 units, FFP 6 units, leukocyte-depleted platelet concentrates 6 units and cryoprecipitate 6 units for 11 hours 30 minutes. On postoperative day 1 , the TTE revealed moderate mitral regurgitation and dynamic LVOTO with SAM. An emergency operation was performed on postoperative day 2 due to persistent bleeding. The patient's postoperative course was complicated by septic shock due to the cellulitis of both thighs. Doppler ultrasonography showed sluggish flow of the hepatic vein, portal vein and hepatic artery. Eventually, the patient expired on postoperative day 69.

\section{Discussion}

Dynamic LVOTO in a structurally normal heart has been described in the medical literature [3-5], Aniskevich et al. [7] reported that a dynamic LVOTO with SAM developed intraoperatively in a patient with a normal stress echocardiogram preoperatively and who underwent LT. In addition, although performing preoperative dobutamine stress echocardiography for cardiac evaluation seems to be valuable to predict adverse cardiovascular events after LT $[8,9]$, the incidence and prognosis of dynamic LVOTO during LT are still unknown. Further, the preoperative degree of the peak pressure gradient in a patient with LVOT does not necessarily predict the outcome and the presence of dynamic LVOTO is not a contraindication for LT [10].

Patients with end stage liver disease usually demonstrate a hyperdynamic state. In addition, LT is associated with further decreases in the left ventricular preload secondary to intraoperative bleeding or surgical interruption of the inferior vena cava (the preanhepatic and anhepatic period) and the decrease of systemic vascular resistance after recirculation of the donor liver (the postreperfusion period) [11]. Therefore, the patients undergoing LT often have several risk factors for dynamic LVOTO and this may be precipitated by hypovolemia in combination with a hyperdynamic state that is induced by catecholamine administration. In case 1 , hemodynamic instability developed immediately after the start of the anhepatic period and the dynamic LVOTO might have been triggered by hypovolemia, as evidenced by the low CVP and RVEDV, which are the parameters of the intravascular volume status (Table 1).

The anesthetic management of hypovloemia is aggressive volume therapy, and the left ventricular end-diastolic volume can be improved with aggressive intravascular volume loading to increase the preload. Yet the diastolic dysfunction in case 1 deterred us from performing aggressive volume therapy for fear of congestive heart failure until the exact volume status of the heart was confirmed by TEE. Moreover, in the case of a small graft volume-to size when performing LDLT, excessive volume during reperfusion could also damage the sinusoids in the grafted liver. These reasons make the fluid management more delicate and it had to be done in a sophisticated manner. For case 1, the cardiac evaluation with TEE guided us to change the therapeutic directions by discontinuing the epinephrine infusion and then start fluid loading. We next used phenylephrine to increase the systemic vascular resistance and esmolol (an ultrashort acting beta-blocker) to improve the degree of obstruction by decreasing both the chronotropic and inotroic state of the left ventricle and inhibiting the profound beta-adrenergic mediated splanchnic vasodilation that is common in patients with end stage liver disease. For case 2, since we noticed the LVOTO before operation, we chose norepinephrine instead of other inotropics and we created portocaval shunt at the early stage of the anhepatic period to minimize the mesenteric venous pooling. As a result, the hemodynamic stability was maintained throughout the surgery.

The TEE played an important role in diagnosing and managing the dynamic LVOTO in our cases. The choice of drug and the amount of fluid challenge were guided by the findings of TEE. During the reperfusion period, which is the most critical period of LT, the cardiac output measured by the thermodilution technique can be inaccurate due to thermal gradients in the venous flow from the cold liver and also due to the rapid changes in cardiac function with time constants that are shorter than that for calculating the cardiac output [12]. In contrast, TEE provides continuous monitoring of the cardiac function and it facilitates appropriate management.

The presence of esophageal varices was previously thought to be a contraindication for TEE, but several studies demonstrated the safe use of TEE in these patients [13,14]. Based on these studies, TEE appears to be safe in patients with varices and its use must be strongly considered in patient with cardiac problems.

In conclusion, dynamic LVOTO should be ruled out in patients with refractory hemodynamic instability during LT although no evidence of LVOTO is found on the screening echocardiography. Moreover, intraoperative TEE is highly useful for confirming dynamic LVOTO and to provide the surgeon with therapeutic guidance.

\section{References}

1. Maron BJ, Bonow RO, Cannon RO 3rd, Leon MB, Epstein SE. Hyper- 
trophic cardiomyopathy. Interrelations of clinical manifestations, pathophysiology, and therapy (1). N Engl J Med 1987; 316: 780-9.

2. Come PC, Bulkley BH, Goodman ZD, Hutchins GM, Pitt B, Fortuin NJ. Hypercontractile cardiac states simulating hypertrophic cardiomyopathy. Circulation 1977; 55: 901-8.

3. Auer J, Berent R, Weber T, Lamm G, Eber B. Catecholamine therapy inducing dynamic left ventricular outflow tract obstruction. Int $\mathrm{J}$ Cardiol 2005; 101: 325-8.

4. Mingo S, Benedicto A, Jimenez MC, Perez MA, Montero M. Dynamic left ventricular outflow tract obstruction secondary to catecholamine excess in a normal ventricle. Int J Cardiol 2006; 112: 393-6.

5. Yang JH, Park SW, Cho SW, Kim HS, Choi KA, Kim HJ. Dynamic left ventricular outflow tract obstruction without basal septal hypertrophy, caused by catecholamine therapy and volume depletion. Korean J Intern Med 2008; 23: 106-9.

6. Aggarwal S, Kang Y, Freeman JA, Fortunato FL Jr, Pinsky MR. Postreperfusion syndrome: hypotension after reperfusion of the transplanted liver. J Crit Care 1993; 8: 154-60.

7. Aniskevich S, Shine TS, Feinglass NG, Stapelfeldt WH. Dynamic left ventricular outflow tract obstruction during liver transplantation: the role of transesophageal echocardiography. J Cardiothorac Vasc Anesth 2007; 21: 577-80.
8. Umphrey LG, Hurst RT, Eleid MF, Lee KS, Reuss CS, Hentz JG, et al. Preoperative dobutamine stress echocardiographic findings and subsequent short-term adverse cardiac events after orthotopic liver transplantation. Liver Transpl 2008; 14: 886-92.

9. De Wolf AM. Preoperative optimization of patients with liver disease. Curr Opin Anaesthesiol 2005; 18: 325-31.

10. Cywinski JB, Argalious M, Marks TN, Parker BM. Dynamic left ventricular outflow tract obstruction in an orthotopic liver transplant recipient. Liver Transpl 2005; 11: 692-5.

11. Costa MG, Chiarandini P, Della Rocca G. Hemodynamics during liver transplantation. Transplant Proc 2007; 39: 1871-3.

12. Lim YC, Doblar DD, Frenette L, Fan PH, Poplawski S, Nanda NC. Intraoperative transesophageal echocardiography in orthotopic liver transplantation in a patient with hypertrophic cardiomyopathy. J Clin Anesth 1995; 7: 245-9.

13. Suriani RJ, Cutrone A, Feierman D, Konstadt S. Intraoperative transesophageal echocardiography during liver transplantation. J Cardiothorac Vasc Anesth 1996; 10: 699-707.

14. Spier BJ, Larue SJ, Teelin TC, Leff JA, Swize LR, Borkan SH, et al. Review of complications in a series of patients with known gastroesophageal varices undergoing transesophageal echocardiography. J Am Soc Echocardiogr 2009; 22: 396-400. 